\title{
Plant
}

\section{Investigation on biochemical and molecular analysis of Echinacea genotypes}

\author{
Esra Maltas ${ }^{1}$, , Aslı Dageri ${ }^{3}$, Hasibe Cingilli Vural ${ }^{2}$, Salih Yildiz ${ }^{1}$ \\ ${ }^{1}$ Department of Chemistry, Faculty of Science, Selcuk University, Konya, Turkey \\ ${ }^{2}$ Department of Biology, Faculty of Science, Selcuk University, Konya, Turkey \\ ${ }^{3}$ Department of Plant Protection, Faculty of Agriculture, Ankara University, Dışkapı, Ankara, Turkey
}

\section{Email address:}

esramaltas@gmail.com (E. Maltas)

\section{To cite this article:}

Esra Maltas, Aslı Dageri, Hasibe Cingilli Vural, Salih Yildiz. Investigation on Biochemical and Molecular Analysis of Echinacea Genotypes. Plant. Vol. 3, No. 1, 2015, pp. 1-7. doi: 10.11648/j.plant.20150301.11

\begin{abstract}
Genotype identification of medicinal plants remains important for botanical drug industry. Limitations of chemical and morphological approaches for authentication have generated need for newer methods in quality control of botanicals. In this study, the difference between Echinacea purpurea and Echinacea pallida were studied by molecular markers. First of all, genomic DNA from Echinacea genotypes was extracted with EZ1 automatic nucleic acid isolation system and was amplified with OPA primer series. The study showed some relationship between six primers (OPA1, OPA2, OPA3, OPA4, OPA6 and OPA15) with productive performance of Echinacea purpurea and Echinacea pallida. However, secondary metabolites and fatty acids of Echinacea purpurea extract were identified by high performance liquid and gas chromatography, respectively. In addition, antioxidant activity associated with chemical structure of the extract was determined by 1,1 1-diphenyl-2-picrylhydrazyl radical scavenging activity.
\end{abstract}

Keywords: Echinacea Purpurea and Echinacea Pallida, Molecular Marker, PCR, nDNA Antioxidant Activity, Fatty acid, Flavonoid

\section{Introduction}

Echinacea is a genus classified in the Heliantheae tribe within the family Asteraceae. Together with other genera in this tribe, Echinacea plants are popularly known to be among the "Coneflowers." The relationship of the genus Echinacea with others has been studied using techniques to determine the degree of relationship and the probable evolutionary development of these plants over time. For several generations, Native Canadians have known the medicinal benefits of Echinacea. It has been well recognized that several species of this popular herb have anti-inflammatory, antibacterial, and antiviral properties (Toselli et al., 2009; Jamison, 2003). Scientific studies have demonstrated that Echinacea is an immune-stimulant that increases the body's ability to resist viral and bacterial infections (Goel et al, 2006; Stanisavljević et al., 2009). There are currently nine known species of Echinacea, three of which have shown to have medicinal properties (Briskin, 2000). The three most sought after species of Echinacea are E. purpurea (L.) Moench, E. angustifolia (D.C.), and E. pallida (Nutt.) Nutt., all of which are very similar in their medicinal properties and morphologies. This has resulted in considerable confusion concerning which species are present in the final marketable product. Analytical research has revealed that there are significant differences in the chemical composition of the medicinally active species. DNA based methods have the potential to become widely employed techniques for rapid identification of species and genotypes (Techen et. al., 2004; Joshi et al., 2004). As scientific studies on the medicinal plants are getting increase to evolve in the 21 st century, the integration of findings from state of the art original morphological, molecular, and phytochemical work by the authors of this article, along with ecological reports and the historical and regulatory literature of the times, suggests that the plants deserve their status as protected resources (Naczk et al., 1998; Amarowicz et al., 2000; Kresovich et al., 1992; Diers and Osborn, 1994; Halldén et al., 1994; Cruz et al., 2007). Moreover, it provides a comprehensive perspective into the biological and political origins of Echinacea materials sourced as phytomedicines, which is long overdue considering the focus on clinical evidence for Echinacea 
health products and dietary supplements related to its phytochemical constitutes such as phenolic acids and flavonoids (Pellati et al., 2004; Baum et al., 2001)

In this study, the difference between Echinacea purpurea and Echinacea pallida were studied by molecular and biochemical markers. First of all, genomic DNA from Echinacea genotypes was extracted with EZ1 automatic nucleic acid isolation system. Obtained DNA from each seed and young leaves were amplified with six OPA primers in thermal cycler by randomly amplified polymorphism DNA (RAPD-PCR) technique. The difference between two genotypes of Echinacea was identified by RAPD-PCR representing polymorfic or nonpolymorfic bands in molecular level. Furthermore, this study demonstrate the ability of RAPD markers to reliably differentiate between different Echinacea genotypes and commercial varieties and also represents an initial but important step in using RAPD markers as a tool for the estimation of genetic diversity in Echinacea genotypes from Turkey. In addition to molecular analysis of Echinacea purpurea, secondary metabolites and fatty acids of its extract were identified by high performance liquid and gas chromatography, respectively. And antioxidant activity of the extract was determined by 1,1-diphenyl-2picrylhydrazyl radical scavenging activity.

\section{Materials and Methods}

\subsection{Molecular Analysis}

\subsubsection{Plant Material}

E. purpurea (L.) Moench and E. pallida (Nutt.) Nutt growing in differrent regions of Turkey and Germany were used for genomic DNA isolation in this study. Plant samples were collected from various forests in the state of Istanbul, Konya and Karadeniz Agricultural Research Institute in Turkey and grown in experimental site. After acclimatization $1 \mathrm{~g}$ of young leaves were harvested fresh for DNA isolation. Shoot tips were wrapped in aluminum foil, labeled, dropped in liquid nitrogen, stored in dry ice for transfer, and then stored in $-80{ }^{\circ} \mathrm{C}$ for latter processing. DNA extracted from Echinacea purpurea was amplified using seven decamer primers, obtained from Operon Technologies Inc. (Almeda CA, USA).

Table 1. RAPD Primers used for the detection of polymorphism in Echinecae species.

\begin{tabular}{ll}
\hline Primer no & Primer Sequence \\
\hline OPA-1 & 5'-CAGGCCCTTC-3' \\
OPA-2 & 5'-TGCCGAGCTG-3' \\
OPA-3 & 5'-AGTCAGCCAC-3' \\
OPA-4 & 5'-AATCGGGCTG-3' \\
OPA-5 & 5'-AGGGGTCTTG-3' \\
OPA-6 & 5'-GGTCCCTGAC-3' \\
OPA-15 & 5'-TTCCGAACCC-3' \\
\hline
\end{tabular}

\subsubsection{Plant DNA Extraction}

Young leaves at seedling stage were harvested for the isolation of genomic DNA. Fresh leaves from 2 individuals of each line/variety were bulked together and the DNA was extracted by following the protocol of Dellaporta, Wood and Hicks (1983). Plant tissue samples were collected from field and glass house, frozen in liquid nitrogen and stored at $-80{ }^{\circ} \mathrm{C}$ or in pots for future use. DNA was extracted from both fresh and stored tissue samples. Furthermore, dried Echinacea sp. seeds were used directly for DNA extraction as they were found to yield DNAs comparable in quality and quantity to that obtained from EZ1 Nucleic Acid Isolation Analyser (QIagen, 2007, author's laboratory or Archeaometry and Biotechnology Lab., Turkey)

\subsubsection{Amount and Purity of DNA}

The extraction yield of DNA per gram of leaf tissue was measured using a UV Spectrophotometer at $260 \mathrm{~nm}$. The purity of DNA was determined by calculating the ratio of absorbance at $260 \mathrm{~nm}$ to that of $280 \mathrm{~nm}$. DNA concentration and purity were also determined by running the samples on $1 \%$ agarose gel based on the intensities of band when compared with the Lambda DNA marker (used to determine the concentration). The nucleic acid concentration was calculated according to the method described by Sambrook, Fritsch and Manniatis (1989).

\subsection{RAPD-PCR Analysis}

DNA was amplified by the RAPD-PCR technique. The $20 \mu \mathrm{l}$ reaction mixture in each tube consisted of $2.5 \mathrm{mM}$ of $\mathrm{MgCl}_{2}, 2 \mu \mathrm{M}$ of each primer, $3 \mu \mathrm{l}$ of $10 \mathrm{xTaq}$ polymerase buffer, $1 \mathrm{U}$ of Taq polymerase (Gibco-BRL), $0.25 \mu \mathrm{M}$ of dNTPs and $\mathrm{ddH}_{2} \mathrm{O}$. All amplification reactions were performed in an BioRad Programmable Thermal Controller programmed with the following program: initial denaturing step at $94{ }^{\circ} \mathrm{C}$ for $5 \mathrm{~min}, 94{ }^{\circ} \mathrm{C}$ for $30 \mathrm{~s}$, anneling $33{ }^{\circ} \mathrm{C}$ at 60 s, $72{ }^{\circ} \mathrm{C}$ for $1 \mathrm{~min}$, next 40 cycles until from 2 to 5 step, 72 ${ }^{\circ} \mathrm{C}$ for $3 \mathrm{~min}$ and a final extension step of $4{ }^{\circ} \mathrm{C}$ until endless. Six 10 mer random primers were used for amplification (primers OPA1-OPA15) and for the OPA5 primer touchdown procedure using by heating at $95{ }^{\circ} \mathrm{C}$ for $4 \mathrm{~min}$, $95{ }^{\circ} \mathrm{C}$ for $1 \mathrm{~min}$, and the annealing step was performed at $35{ }^{\circ} \mathrm{C} 1 \mathrm{~min}, 72{ }^{\circ} \mathrm{C}$ for $2 \mathrm{~min}$ and $72{ }^{\circ} \mathrm{C}$ for $7 \mathrm{~min}$. Temperature was decreased to $34{ }^{\circ} \mathrm{C}$ at $1{ }^{\circ} \mathrm{C}$ per cycle during the first 10 cycles, and the subsequent 35 cycles were performed. Amplified DNA fragments were separeted in a $2 \%$ agarose TBE gel at 150 Volt stained with ethidium bromide and were photographed under Kodak EDAS 290 High Performance UV Transilluminator. RAPD analysis showed high interspecies polymorphism. RAPD analysis of 2 plants (templates DNA) was performed for better evaluation of the extent and patterns of distribution of RAPD diversity in Echinacea. Variability of RAPD markers was tested within cultivars as well. The distribution of genetic variation was high among the cultivars but also within the cultivars. All PCR reactions were run in triplicate, and only reproducible and clear bands were scored. 


\subsection{Biochemical Analysis}

\subsubsection{Sample Preparation}

E. purpurea (L.) seed $(20$ g) were powdered and extracted with methanol for $6 \mathrm{~h}$ at $30^{\circ} \mathrm{C}$ using an orbital shaker. After filtration through a filter paper (Whatman No.1) the solvent was evaporated under vacuum to $10 \mathrm{~mL}$ then dried at $-50^{\circ} \mathrm{C}$ in a lyophiliser. The methanolic extract (yield $11 \%, \mathrm{w} / \mathrm{w}$ ) was stored at $4^{\circ} \mathrm{C}$.

\subsubsection{Analysis of Secondary Metabolites and Fatty Acid}

Two milliliters extract was filtered through a $0.2 \mathrm{~m}$ filter. Five microliters sample was injected using a Shimadzu 1100 series HPLC equipped with a SIL-10AD vp atuosampler and LC-10Advp pump system, diode array detector (DAD), and an Inertsil Agilent Eclipse XDB column $(240 \mathrm{~mm} \times 4,60 \mathrm{~mm} 5 \mu \mathrm{m}$ particle size $)$. Column temperature was $30^{\circ} \mathrm{C}$. The mobile phase components were methanol (A) and 3\% (v/v) aqueous acetic acid (B). The mobile phase program was a linear gradient from $5 \% \mathrm{~A}$ to $66.5 \%$ A over $75 \mathrm{~min}$ at $0.8 \mathrm{~mL} \mathrm{~min}^{-1}$. A series of each phenolic compunds given in Table 2 were analysed quantiatively in order to determine phenolic acids and flavonoids before analysis of the methanolic extract of $E$. purpurea $(\mathrm{L}$.) seed.

Table 2. Fatty acid composition of Echinacea extract as a percent of total (\%).

\begin{tabular}{ll}
\hline Compounds & Amount $\left(\mu \mathbf{g ~ g}^{-1}\right)$ \\
\hline Gallic acid & - \\
Catechin hydrate & - \\
Caffeic acid & $25.4 \pm 2.3$ \\
Epicatechin & - \\
p-coumaric acid & $3.2 \pm 0.4$ \\
Ferulic acid & - \\
Vitexin & - \\
Rutin & - \\
Hesperidin & - \\
Rosmarinic & - \\
Eriodictyol & - \\
Quercetin & - \\
Naringenin & $11.8 \pm 1.2$ \\
Carvacrol & - \\
\hline
\end{tabular}

Data expressed as means \pm standard deviation $(n=3)$.

Fatty acid composition was carried out on a Shimadzu GC 5050 gas chromatography. The chromatographic column for the analysis was a Cp Wax 52 CB capillary column $(50 \mathrm{~m} \backslash 0,32 \mathrm{~mm}, 1,2 \mu \mathrm{m})$. The carrier gas used was helium at a flow rate of $10 \mathrm{psi} / \mathrm{min}$. The methanolic extract of the seed was derivatived with $5 \%(\mathrm{w} / \mathrm{v})$ sodium methoxide overnight.

\subsubsection{DPPH Radical Scavenging Assay}

This assay was carried out as described by Sanchez Moreno et al., 1958 with some modifications; $0.1 \mathrm{ml}$ of the extracts/fractions was placed in a cuvette and $0.5 \mathrm{ml}$ of a methanolic solution of DPPH $(0,004 \%)$ was added. After $30 \mathrm{~min}$, absorbance at $517 \mathrm{~nm}$ was determined using a spectrophotometer (Shimadzu Co. Ltd., Kyoto, Japan). A blank experiment was also carried out applying the same procedure to a solution without the test material and the absorbance was recorded as $A_{\text {blank }}$. The free radicalscavenging activity of each solution was then calculated as percent of inhibition according to the following equation: inhibition of the free radical by DPPH $(I \%)$ was calculated using the following equation described by Kartal et al., 2007.

$$
I \%=\left[\left(A_{\text {blank }}-A_{\text {sample }}\right) / A_{\text {blank }}\right] \times 100
$$

where $A_{\text {blank }}$ is the absorbance of the blank (containing all reagents except the extract or standard), and $A_{\text {sample }}$ is the absorbance of the extract or standard. Experiments were carried out in triplicate and also-butylated hydroxytoluene (BHT) and butylated hydroxyanisol (BHA) were also used as standard antoxidants.

\subsection{Statical Analysis}

In this study, polymorphic bands were scored as binary data (present $=1$; absent $=0$ ) usefulness of across the genotypes to generate a binary data matrix. The matrix was then used to generate a Genetic similarity (GS) matrix based on Jaccard's coefficient of similarity (Jaccard, 1908). In brief, GS $(i j)=2 a /(2 a+b+c)$, where GS (ij) is the measure of genetic similarity between individuals $i$ and $j$, $a$ is the number of polymorphic bands that are shared by $i$ and $j, b$ is the number of bands present in $i$ and absent in $j$, and $c$ is the number of bands present in $j$ and absent in $i$. Using this RAPD molecular technique it is now possible to genetically characterize the three commercially relevant Echinacea species. The above images are typical agarose gels demonstrating RAPD profile of E. purpurea and E. pallida with their corresponding RAPD primers. The statistical analysis was carried out by using OriginPro 7.5 software. One way ANOVA was applied to data and results were compared by using Tukey test. A difference was considered to be statistically significant when the $p$-value is lower than $0.05(p<0.05)$.

\section{Result and Discussion}

\subsection{Molecular Analysis}

Herbal medicine has been enjoying renaissance among the customers throughout the world. However, one of the impediments in the acceptance of these formulations is the lack of standardization and quality control. Due to the complex nature and inherent variability of the chemical constituents of plant-based drugs, it is difficult to establish quality control parameters. We initially choose over seven random decamer primers to generate RAPD profiles of the Echinacea genotypes. This study shows that if assay conditions are carefully controlled, the RAPD methodology genomic DNA-based RAPD methodology to assess the genetic may provide a cheap, rapid, and effective means to evaluate the genetic diversity among a large number of plant populations and help devise sampling strategies to 
complement classical morpho-agronomic descriptors. The results presented in this study demonstrate the utility of using RAPD markers to characterize interspesific relationships, to evaluate the germplasm diversity in Echinacea species, to identify potential sources of unique germplasm material, and to identify the presence of spesific adulterans in botanical samples. Therefore, our major objective was to develop molecular tools for accurate identification of different components present in herbal formulations. Random Amplified Polymorphic DNA (RAPD) involves the use of a single 'arbitrary' primer in a polymerase chain reaction (PCR) and results in the amplification of several discrete DNA products (Williams et.al., 1990). Each product is derived from a region of the genome that contains two short segments in inverted orientation, on opposite strands that are complementary to the primer and sufficiently close together for the amplification to work (Kapteyn et. al., 2002). The assay will be helpful in quality control of herbal medicines in the market.

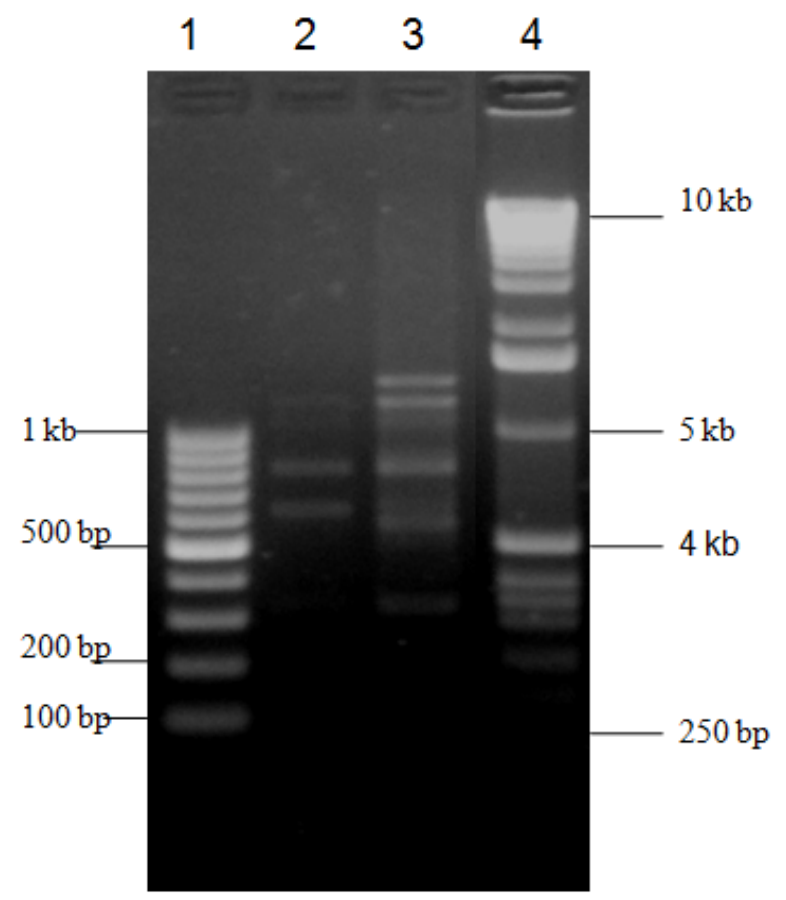

Figure 1. Agarose gel electrophoresis of OPA 15 gene RAPD- PCR products. Respectively, Lane 1, 100 bp ladder size standard or marker and Lane 4, 1000 bp ladder size standard or marker, Lane 2, plant sample genomic DNA PCR product with E. purpurea growing in the Black Sea Region by manuel isolation. Lane 3, plant sample genomic DNA PCR product with E. purpurea growing in İzmir, Ödemiş by Bio Robot EZ1.

Samples analysed included dried Echinacea samples were used directly for DNA extraction as they were found to yield DNAs comparable in quality and quantity using EZ1 nucleic acid isolation analyser (QIAGEN, 2007). The results showed that: OPA1, OPA2, OPA3, OPA4, OPA6 and OPA15 are RAPD markers correlated with the performance of Echinacea species. It showed that those markers might be linked with the dominant effect gene which controls those reproductive performances, or those markers might have the effect of one-gene-multi-effect. It can provide reliable theoretical basis for the molecular breeding in our country. If those markers could be further utilized in construction of molecular linkage mapping, gene location and molecular marker can help selection as well. Amplification of the genomic DNA from each genotypes using all the six decamer primers revealed a variety of RAPD patterns in this study. The products of this amplification reaction with primer OPA15 is shown in Figure 1. The arrows mark three fragments (300 bp, $600 \mathrm{bp}$ and $800 \mathrm{bp}$ ) that are amplified from only two of the samples tested. Furthermore, the products of this amplification reaction with primer OPA1, OPA2, OPA3, OPA4, OPA6 are shown in Figure 2. The arrows mark two fragments (600 bp and $800 \mathrm{bp}$ ) that are amplified from two of the samples tested. Comparing Echinacea genotypes, 6 fragments (OPA1, OPA2, OPA3, OPA4, OPA6 and OPA15) were identified as markers potentialy related to the herbal drog gene in Echinacea purpurea and Echinacea pallida and selective marker in between species that will be confirmed through a genetic segregation study. That is to say, OPA1, OPA2, OPA3, OPA4, OPA6 and OPA15 were showed same band profiles for two different species in agarose gel imaging. OPA5 is a universal molecular RAPD marker for phylogeny.

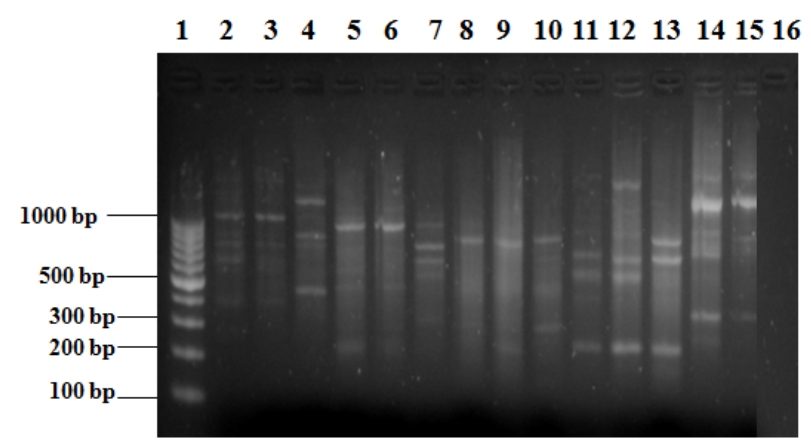

Figure 2. Agarose gel electrophoresis of OPA 1, 2, 3, 4, 6 gene RAPD$P C R$ products. Respectively, Lane 1, $1000 \mathrm{bp}$ ladder size standard or marker, Lane 2, 3 and 4 amplified PCR products using OPA1, Lane 5, 6, 7 amplified PCR products using OPA 2, Lane 8, 9 and 10 amplified PCR products using OPA 3, Lane 11, 12 and 13 amplified PCR products using OPA 4 Lane 14 and 15 amplified PCR products using OPA 6, Lane 16, negative control or none DNA.

It is now possible to genetically characterize the two commercially relevant Echinacea species by using this RAPD molecular technique. The images are typical agarose gels demonstrating RAPD profile of E. purpurea, and $E$. pallida with their corresponding RAPD primers. The assay will be helpful in quality control of herbal medicines in the market. The technique was proved to contribute to the identification of components in Ayurvedic herbal preparation and thus helping to serve as a complementary tool for quality control. RAPD markers revealed their ability to produce polymorphisms among the different accessions. These results means that it is possible distinguish the accessions by this technique and evaluate 
the genetic diversity of the material. Further studies are in progress with the aim to characterize all the accessions.

\subsection{Biochemical Analysis}

DPPH (1,1-diphenyl-2-picrylhydrazyl) radical scavenging activity measures hydrogen-donating ability of antioxidants (Liu et al., 2007) Activity is measured as the relative decrease in absorbance of DPPH as it reacts with the antioxidant (Fagali and Catalá, 2008). Huang and coworkers (2004) also noted that activity starts to decrease with increasing concentration after a critical point and attributed it to interfering substances. DPPH radical scavenging activity was plotted as a function of sample concentration in Figure 3. DPPH radical scavenging activity was observed to increase with sample concentration sigmoidally between 0.1 and $1 \mathrm{mg} \mathrm{mL}^{-1}$ of sample. The results indicated that DPPH radical scavenging activity reaches a saturation point at high concentrations. Antioxidant activity was evaluated with $\mathrm{EC}_{50}$ values, the concentration at which radical scavenging activity is $50 \%$, is calculated from the graph plotting inhibition percentage against extract concentration. $\mathrm{EC}_{50}$ values of Echinacea purpurea compared to those of the standard antioxidants, BHA and BHT. High $\mathrm{EC}_{50}$ values indicated low antioxidant activity in DPPH method. The results indicated that $I C_{50}$ values of the extract and standards, BHT and BHA, were $0.41 \pm 0.04, \quad 0.020 \pm 0.001$, and $0.035 \pm 0.007 \mathrm{mg} \mathrm{mL} \mathrm{m}^{-1}$, respectively $(p<0.05)$.

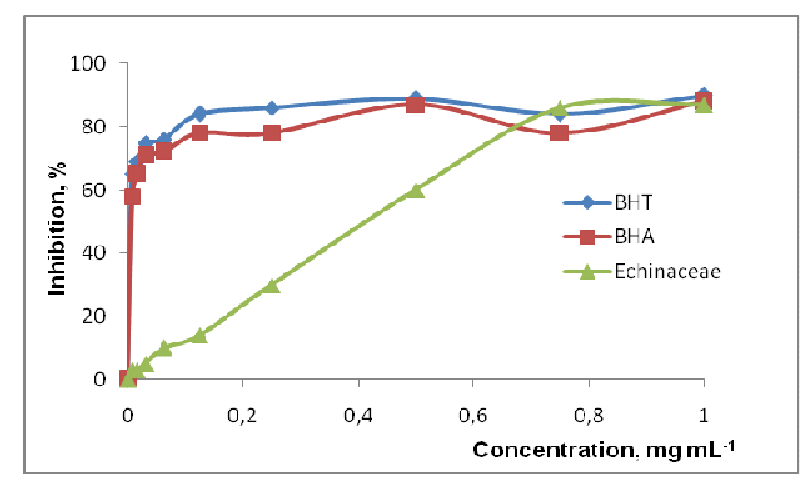

Figure 3. Inhibition ratio (\%) against increasing concentration of Echinacea extract and standards, BHT and BHA, in DPPH assay $(p<$ 0.05).

Phenolic compounds such as phenolic acids, flavonoid, anthociyanidins, and polyphenolics naturally occur in fruits, vegetables and the other plants. Typical phenolics that possess antioxidant activity have been characterized as phenolic acids and flavonoids (Chen et al. 1997; Amarowicz et al., 2000; Stanisavljević et al., 2009). HPLC analysis was carried out to identify the phenolic profiles in Echinacea purpurea extract. Two major phenolic metabolites were found to be as caffeic acid with $25.4 \pm 2.3$ and naringenin with $11.8 \pm 1.2$ (Table 2). But, the lowest content of the extract was coumaric acid with $3.2 \pm 0.4$. In addition to phenolic acids and flavonoids, conjugated double bonds made important contributions to the radical scavenging capacity of certain fatty acids (Yurawecz et al. 1995; Chen et al. 1997; MacDonald et al. 2000). Conjugated linoleic acid (CLA) can readily donate an electron or hydrogen to form a CLA free radical intermediate due to resonance delocalization. CLA isomers showed capacity to directly react and quench free radicals as measured by photoemission and spectrophotometric methods (Fagali and Catala, 2008). Gas chromatographic analysis of Echinacea purpurea extract revealed the presence of 8 fatty acids. Table 3 showed that the main compounds of the methanolic extract were linoleic acid (18:2) with $43.21 \pm 2.71 \%$ and oleic acid (C 18:1) with $14.15 \pm 1.54 \%(\mathrm{w} / \mathrm{w})$. In contrast, the lowest fatty acid of the extract was palmitoelic acid (C 16:1). The extract had polyunsaturated fatty acids with $47.11 \pm 4.40 \%(\mathrm{w} / \mathrm{w})$ as omega-3 and omega- 6 fatty acids. In addition to fatty acids, two acids were identified as levulinic acid and fumaric acid in the extract by GC analysis.

Table 3. Content of the extract of several phenolic acids and flavonoids of Echinacea extract.

\begin{tabular}{|c|c|c|}
\hline Fatty acids & Extract (\%) & Retention time (min.) \\
\hline $\begin{array}{l}\text { Fumaric Acid Dimethyl } \\
\text { Ester }\end{array}$ & $0.15 \pm 1.24$ & 14,9 \\
\hline Levulinic acid ME & $0.57 \pm 0.03$ & 15,2 \\
\hline C $14: 0$ & $1.12 \pm 0.18$ & 28.4 \\
\hline C 16:0 & $19.22 \pm 1.68$ & 43.8 \\
\hline C 17:0 & $1.30 \pm 0.54$ & 50.8 \\
\hline C $18: 0$ & $7.49 \pm 0.88$ & 54.7 \\
\hline$\Sigma$ SFAs $^{a}$ & $29.13 \pm 1.54$ & \\
\hline C $16: 1$ & $0.27 \pm 1.24$ & 45.4 \\
\hline C $18: 1$ & $14.15 \pm 1.54$ & 56.0 \\
\hline$\Sigma$ MUFAs $^{a}$ & $14.42 \pm 2.78$ & \\
\hline C $18: 2$ & $43.21 \pm 2.71$ & 58.1 \\
\hline C $18: 3$ & $3.93 \pm 1.69$ & 60.9 \\
\hline PUFAs $^{a}$ & $47.11 \pm 4.40$ & \\
\hline
\end{tabular}

Data expressed as means \pm standard deviation $(\mathrm{n}=3)$.

aSFAs; Saturated fatty acids, MUFAs; Monounsaturated fatty acids, PUFAs; Polyunsaturated fatty acids.

In conclusion, molecular-weight markers were used to estimate the sizes of amplification products and to compare duplicate reactions. A set of random 10-mer primers was purchased from Invitrogen Firm. After screening, six primers that amplified clear, reproducible banding patterns were chosen for further studies. RAPD assays were repeated twice for each primer and only the reproducible bands were scored, with specific attention to the repeatability of polymorphic bands. The presence or absent of bands was scored by eye and Quantity One system and only unequivocal bands were scored, The weak and spurious bands was not included. PCR amplification was successful for altogether the genotypes.

Evaluation of genetic diversity in the plants had been carried out using various techniques consisted of morphological, protein, isozyme and DNA-based markers (Shengwu et al., 2003). DNA-based markers are a powerful tool for studies of genetic diversity; therefore it is used for genetic studies and evaluation of genetic diversity. One of 
the suitable DNA-based markers for genetic diversity studies is RAPD (Random Amplified Polymorphic DNA) (Lie-Zhao, 2006). However, combination of genetic engineering and analytical techniques, and biochemical analysis in addition to classic methods, have made it possible to produce new varieties of Echinacea. Improvement of Echinacea and extension of its cultivation areas have recently received priority in Turkey. It is concluded that Echinacea purpureae growing in Turkey exhibited high antioxidant activity with high phenolic acids and flavonoid content associated with its genome structure and climatical changes that may be prefered to seed in order to improve seed quality for usage in food industry as a natural source.

\section{Acknowledgement}

We thank Scientific Research Foundation of Selcuk University (BAP) for providing foundation. Fresh, seed, plantlets and as well as herbarium specimens were used for DNA extraction in this study. Herbarium samples were collected by the author in the field gathered in herbaria, Konya, Turkey. We thank BioRad Company for excellent technical assistance.

\section{References}

[1] Amarowicz R, Naczk M and Shahidi F (2000) Antioxidant Activity of Crude Tannins of Canola and Rapeseed Hulls. JAOCS 77: 957-961.

[2] Baum BR, Mechanda S, Livesey JF, Binns SE, Arnason JT (2001) Predicting quantitative phytochemical markers in single Echinacea plants or clones from their DNA fingerprints. Phytochem. 56 (6): 543-549.

[3] Briskin DB (2000). Medicinal plants and phytomedicines. Linking plant biochemistry and physiology to human health. Plant Physiol. 124:507-514.

[4] Chen ZY, Chan PT, Kwan KY and Zhang A (1997) A reassessment of the antioxidant activity of conjugated linoleic acid. J. Am. Oil Chem. Soc. 73: 749-753.

[5] Cruz VM, Luhman VR, Marek LF, Rife CL, Shoemaker RC, Brummer EC and Gardner CAC (2007) Characterization of flowering time and SSR marker analysis of spring and winter type Brassica napus L. germplasm. Euphytica 153: 43-57.

[6] Dellaporta SL, Wood J and Hicks JB (1983) A plant DNA minipreparation: Version II. Plant Mol. Biol. Rep. 1: 19-21.

[7] Diers BW and Osborn TC (1994) Genetic diversity of oilseed Brassica napus germplasm based on restriction fragment lenght polymorphism. Theor. Appl. Gen. 88: 662668 .

[8] Fagali N and Catalá A (2008) Antioxidant activity of conjugated linoleic acid isomers, linoleic acid and its methyl ester determined by photoemission and $\mathrm{DPPH} \bullet$ techniques. Biophysical Chem. 137: 56-62.
[9] Goel V, Chang C, Slama JV, Barton R, Bauer R, Gahler R, Basu TK (2002) Alkylamides of Echinacea purpurea stimulate alveolar macrophage function in normal rats. International Immunopharmacology, 2 (2-3:)381-387.

[10] Haldén C Nilsson NO, Rading I, Säll T (1994) Evaluation of RFLP and RAPD markers in a comparison of Brassica napus breeding lines. Theoretical and Applied Genetics 88: 123-128.

[11] Huang DJ, Lin CD, Chen HJ, Lin YH (2004) Antioxidant and antiproliferative activities of sweet potato (Ipomoea batatas [L.] Lam 'Tainong 57') constituents. Botanical Bulletin of Academia Sinica, 45: 179-186.

[12] Jaccard P (1908) Novelles recgerches sur la distribution florale. Bull. Soc. Vaud. Sci. Nat. 44: 223-270.

[13] Jamison JR (2003) Echinacea. Clinical Guide to Nutrition \& Dietary Supplements in Disease Management, 501-505.

[14] Joshi K, Chavan P, Warudee D, Patwardhan B. (2004). Molecular markers in herbal drug technology. Current Science 87: 157-165.

[15] Kapteyn J, Goldsbrough PB and Simon JE (2002) Genetic relationships and diversity of commercially relevant Echinacea species. Theor. Appl. Genet. Berlin; SpringerVerlag. Aug 2002. v. 105 (2/3) p. 369-376.

[16] Kresovich S, Williams JGK, McFerson JR, Routman EJ, Schaal BA (1992) Characterization of genetic identities and relationships of Brassica oleracea L. via random amplified polymorphic DNA assay. Theoretical and Applied Genetics 85: 190-196.

[17] Lie-Zhao L, Jin-Ling M, Na L, Li C, Zhang-Lin T, Xue-Kun Z, Jia-Na LI (2006) QTL Mapping of Seed Coat Color for Yellow Seeded Brassica Napus. Actu GeneticaSinica, 33: 181-187.

[18] Liu X, Dong M, Chen X, Jiang M, Lv X and Yan BG (2007) Antioxidant activity and phenolics of an endophytic Xylaria sp. from Ginkgo biloba. Food Chem. 105 (2) 548-554.

[19] MacDonald HB (2000) Conjugated linoleic acid and disease prevention: a review of current knowledge, J. Am. Coll. Nutr. 19: 111-118.

[20] Naczk M, Amarowicz R, Sullivan A and Shahidi F (1998) Current Research Developments on Polyphenols of Rapeseed/Canola: A Review, Food Chem. 62: 489-502.

[21] Pellati F, Benvenuti S, Magro L, Melegari M, Soragni F (2004) Analysis of phenolic compounds and radical scavenging activity of Echinacea spp. Journal of Pharmaceutical and Biomedical Analysis 35(2): 289-301

[22] Sambrook J, Fritsch EF, Manniatis T (1989). Molecular Coloning: A Laboratory Manual, 15 section, p. 18.47-18.76. Cold. Spring Harbor, New York.

[23] Sanchez-Moreno C, Larrauri JA, Saura-Calixto F (1998) A procedure to measure the antiradical efficiency of polyphenols. J. Sci. Food Agric. 76: 270-276.

[24] Shengwu H, Ovesná JK, Kučera V and Vyvadilová M (2003) Evaluation of genetic diversity of Brassica napus germplasm from China and Europe assessed by RAPD markers. Plant Soil Environ. 49 (3): 106-113. 
[25] Stanisavljević I, Stojičević S, Veličković D, Veljković V, Lazić M (2009) Antioxidant and Antimicrobial Activities of Echinacea (Echinacea purpurea L.) Extracts Obtained by Classical and Ultrasound Extraction. Chinese Journal of Chemical Engineering, 17(3): 478-483.

[26] Techen N, Crockett SL, Khan IA, Scheffler BE (2004) Authentication of Medicinal Plants Using Molecular Biology Techniques to Compliment Conventional Methods. Curr. Med. Chem., 11, 1391-1401.

[27] Toselli F, Matthias A, Gillam EMJ (2009) Echinacea metabolism and drug interactions: The case for standardization of a complementary medicine. Life Sciences, 85( 3-4): 97-106.
[28] Yurawecz MP, Hood JK, Mossoba MM. Roach JA, Ku Y (1995) Furan fatty acids determined as oxidation products of conjugated octadecadienoic acid. Lipids 30: 595-598.

[29] Welsh J, Peterson C, Clelland MMc (1991) Polymorphisms generated by arbitrarily primed PCR in the mouse: application to strain identification and genetic mapping. Nucleic Acids Res. 19: 303-306.

[30] Williams JGK, Kubelik AR, Livak KJ, Rafalski JA and Tingey SV (1990) DNA polymorphisms amplified by arbitrary primers are useful as genetic-markers. Nucleic Acids Res. 18: 6531-6535. 